\title{
Autonomous vehicles: Developing a public health research agenda to frame the future of transportation policy
}

\author{
Travis J. Crayton ${ }^{\mathrm{a}}$, Benjamin Mason Meier ${ }^{\mathrm{b}, *}$ \\ a Department of City and Regional Planning, University of North Carolina at Chapel Hill, New East Building, Campus Box \#3140, Chapel Hill, NC \\ 27599-3140, United States \\ b Department of Public Policy, University of North Carolina at Chapel Hill, Abernethy Hall, Campus Box \#3435, Chapel Hill, NC 27599-3435, United \\ States
}

\begin{abstract}
A B S T R A C T
Recent advancements in autonomous vehicle technology have led to projections that fully autonomous vehicles could define the transportation network within the coming years. In preparation for this disruptive innovation in transportation technology, transportation scholars have started to assess the potential impacts of autonomous vehicles, and transportation policymakers have started to formulate policy recommendations and regulatory guidance concerning their deployment. However, there has been little analysis of the public health implications arising from the widespread adoption of fully autonomous vehicles. We examine these prospective public health impacts-both benefits and harms to individual and population health-and analyze how they can be considered in the development of transportation policy. In this manuscript, we discuss the evolving relationship between technological innovations in transportation and public health, conceptualize automated transportation as a disruptive technology necessitating a public policy response, and define a research agenda to examine the public health implications of autonomous vehicle policy, as seen through existing evidence on road casualties, environmental health, aging populations, non-communicable disease, land use, and labor markets. We conclude that such a public health research agenda would provide a basis to frame autonomous vehicle policies that best support the public's health, realize the United Nations Sustainable Development Goals to ensure healthy lives and create sustainable cities, and provide a basis for public health participation in transportation policy reforms.
\end{abstract}

\section{Introduction}

As technological innovations are increasingly marketed with ambitious claims to solve problems that do not yet exist, one evolving technology stands out for its capacity to meet its promised expectation of changing everything for everyone: autonomous vehicles. These autonomous vehicles, operating without direct human input, promise to revolutionize transportation throughout the world, and as a consequence, have the capability to fundamentally alter individual behaviors, built environments, labor markets, and other determinants of health. With national policies allowing for greater regulatory freedom in the rapid advancement of these new technologies, such revolutionary promise creates an imperative for greater interdisciplinary understanding of the public health implications of autonomous vehicle policy.

Recent innovations in autonomous vehicles—also referred to as automated vehicles or self-driving vehicles-are already changing

\footnotetext{
* Corresponding author.

E-mail address: bmeier@unc.edu (B.M. Meier).
} 
the transportation landscape, fueled by advances in computer technology companies such as Google, automobile manufacturing companies such as Tesla, and transportation network companies such as Uber. Policymakers have sought to conceptualize these groundbreaking new vehicles across an automation continuum, with each degree of automation raising new transportation policy implications. Early field tests have shown the potential for autonomous vehicles to drive alongside human-directed vehicles, with many in the industry predicting fully autonomous vehicles in widespread use throughout the world in the coming decade. As technology continues to advance across the spectrum of automation in the coming years, moving in an inexorable shift toward the complete automation of transportation, there is an increasing need to develop multisectoral policy guidance to prepare for the realization of an autonomous transportation grid. With automated vehicles posing both promise and risk to the public's health, it is imperative that public health considerations be taken into account and public health stakeholders be participants in autonomous vehicle policymaking.

This article assesses potential areas of public health benefits and public health harms arising from this transportation revolution, outlining a public health research agenda to frame autonomous vehicle policy. The background section below outlines the evolving relationship between vehicular transportation and public health, reviewing public health evidence across past transportation advancements. With automated transportation representing a fundamental break from the past evolution of transportation technologies, the analysis section conceptualizes automated transportation as a disruptive technology that will necessitate new policy responses. Laying out a public health research agenda to understand this disruptive technology, this article outlines the research necessary to examine the public health implications of autonomous vehicles, as seen through existing evidence on road casualties, environmental health, aging populations, non-communicable diseases, land use, and labor markets. The authors conclude that such a public health research agenda would provide an evidentiary basis to frame transportation policies that best support the public's health.

\section{Background - transportation policy as a determinant of health}

Advances in transportation technologies have long had sweeping (if often under-recognized) influence on the economic and social factors that shape individual and population health (Khreis et al., 2016; Widener and Hatzopoulou, 2016). The adoption of new transportation technologies over time has driven significant public health impacts, and, increasingly, urban planners and public health researchers have come together to analyze these implications in the development of transportation policy (e.g., Boehmer et al., 2016; Boniface et al., 2015; Frank et al., 2006; Krzyzanowski et al., 2005; Mindell, 2014; Morrison et al., 2003; Woodcock et al., 2009). Through the evolution of policy guidance focused on health, including health impact assessments, policymakers and practitioners now have tools to incorporate the consideration of public health impacts into the development and implementation of transportation policy (CDC, 2012; Dannenberg et al., 2014).

Examining the past development of transportation policy, planning scholars in the United States (Adams, 1970; Muller, 2004) have conceptualized modern transportation history as being defined by four distinct eras of transportation technologies:

1. Walking-Horsecar Era (1800-1890)

2. Electric Streetcar Era (1890-1920)

3. Recreational Automobile Era (1920-1945)

4. Freeway Era (1945-Present)

Each era has presented unique challenges to the public's health.

During the walking-horsecar era, horse manure presented the most recognized public health challenge (McShane and Tarr, 2003). Early analyses acknowledged the significant obstacles that manure posed to urban health, particularly as a breeding ground for disease, and policymakers debated an evolving set of policies to regulate proper manure disposal (Hall, 1914, 1918). This public health crisis would not be resolved until the widespread use of electric streetcars rendered horses obsolete as a primary mode of transportation (Hilton, 1969).

Over the course of the electric streetcar era, facilitated by public policies designed to encourage private streetcar franchising, technological advancements encouraged population dispersion into less-dense, suburban locations outside of the urban core (Wells, 2014). These suburban development trends provided benefits, such as a reduced risk of infectious disease and improved air quality to those who moved into these areas, that fueled declines in urban populations and improvements to public health during this era (Beauregard, 2009). This changing spatial distribution, facilitated by streetcars and encouraged through policy, set the stage for widespread automobile adoption and established population distribution patterns that continue to influence public health today.

Automobile adoption, accompanied by changing suburban land use development patterns, provided unprecedented freedom of mobility (Muller, 2004). Such freedom in the recreational automobile era, accompanied by cleaner living conditions and improved environmental health in lower density suburbs, facilitated improved public health; however, by the 1920s, the negative health implications of automobile use had begun to attract public health research (Chesley, 1924). As automobile use increased, the editorial board of the American Journal of Public Health called for researchers to devote more attention and analysis to traffic fatalities, automobile design, and health impacts (Atwater et al., 1938).

Advancement into the modern freeway era has seen an expanding public health research focus on the proximal and distal impacts of our automobile-centric transportation system. Vehicle collisions remain a leading cause of injury and death throughout the world, with large inequities in automobile-related morbidity and mortality across countries (Frumkin, 2002). The adverse health impacts of air pollution are increasingly recognized in the public health literature, with automobile-generated greenhouse-gas emissions seen to 
contribute significantly to climate change (Dora, 1999; Dora and Phillips, 2000; Frumkin, 2002). Reliance on the automobile for travel—and the construction of a built environment designed around automobile use-has also significantly reduced physical activity and increased sedentary behaviors, with increased obesity contributing to a dramatic rise in non-communicable diseases throughout the world (Ding et al., 2014).

Despite these negative public health implications, widespread automobile use has also created significant economic and social opportunities, with the livelihoods of billions tied to vehicular transportation and the use of automobiles central to human development (World Bank, 1994). Responding to the harms of automobile use, technological advancements and regulatory efforts have mitigated some of the negative impacts and sought to improve health and well-being in an automobile-centric world. For example, documentation of the negative health implications of lead in gasoline has supported policies across countries to shift toward the use of only unleaded gasoline (Thomas, 1995). Research into traffic fatalities has led to improved safety, with the adoption of policies requiring seatbelt use, enhanced enforcement against impaired driving, and improved safety technologies to protect passengers in the event of a crash (Lee, 2008). Policies on fuel economy have sought to reduce carbon emissions as a means to mitigate the cataclysmic effects of global climate change (Chapman, 2007).

The development and implementation of transportation policy has produced marked impacts on public health, and it is crucial that public health considerations inform the future formulation of transportation policy (Giles-Corti et al., 2016). As technological advancements in automation continue toward fully autonomous vehicles, policymakers have an opportunity to ensure that public health impacts are evaluated and addressed in the formulation of autonomous vehicle policy.

\section{Analysis - autonomous transportation as disruptive innovation}

With almost one billion vehicles on the planet, a number that is expected to double in the next decade (Sperling and Gordon, 2009), the promise of automation could rapidly prove ubiquitous in select parts of the world, with far-reaching social, economic, and environmental ramifications from these "smart" cars and trucks. Yet, while automated transportation represents a "disruptive innovation," upending the existing transportation market and business model, this revolutionary change in transportation will occur incrementally (Christensen and Raynor, 2003). Driving assistance features are already in the market (from adaptive cruise control to lane departure warnings to parking assist systems), and these features are often seen as stepping-stones (technologically and societally) to fully automated transportation (Fagnant and Kockelman, 2015). The implementation of fully autonomous vehicles will not be uniform, advancing incrementally in the degree of automation and in the adoption across countries (NHTSA, 2013). A fully autonomous transportation grid will build upon these incremental advances and, without any direct human input, promises to maximize safety, convenience, and efficiency in ways that will affect all facets of life.

The policy transition from traditional to autonomous vehicle regulation will be correspondingly incremental, requiring continuous reforms to accommodate changes in technology and infrastructure. As fully autonomous vehicles enter the roadways, they will be sharing the roads with human drivers for the near future (Fagnant and Kockelman, 2015). While there remain myriad barriers to mass-market penetration of autonomous vehicles, the potential societal benefits (at both the individual and population level) are likely to facilitate a wholesale transition in transportation toward completely automated roadways (Thompson, 2016). Should roadways become completely autonomous, this fully automated grid will present a new set of prospective risks and benefits, and such a context will require a new set of transportation policy responses (Glancy, 2015).

Where policymakers had not considered autonomous vehicles until the past decade, there has been a recent burst of policy efforts to regulate these disruptive technologies (Anderson et al., 2016). With these technological changes advancing rapidly in the coming years (driven by market incentives and regulatory exemptions), it will be necessary for public health actors to engage with these policy reforms-from distinct local regulations to preempting national law-to assure the public health benefits of autonomous transportation (Fleetwood, 2017). Such policy debates will involve a range of regulatory issues, impacting health through:

- Zoning - affecting issues of land use, urban planning, and population density;

- Licensing - for individual owners, ride share services, and commercial fleets;

- Privacy - through sharing of location/use data with government and private actors;

- Costs - with owning/operating costs pushing for demand-management strategies on roadways and increased revenue for infrastructure maintenance;

- Liability - including civil and criminal responsibility for vehicular harm.

Public health issues are implicit in these multisectoral policies, and public health actors should play an essential role in developing and implementing policies that will take account of these public health implications, supporting health benefits while minimizing harms.

\section{Research agenda - public health implications of automated transportation}

Given the public health implications of autonomous vehicle technologies, public health actors have a distinct role to play in framing transportation policy in a way that maximizes the public health benefits. To do so, additional policy research will be necessary to analyze the public health effects of automated vehicles on (1) road casualty prevention, (2) environmental health protection, (3) healthy aging promotion, (4) non-communicable disease reduction, (5) land use regulation, and (6) labor market disruption. These public health impacts can be employed by policymakers in order to frame autonomous vehicle policy in ways most beneficial to health and well-being. 


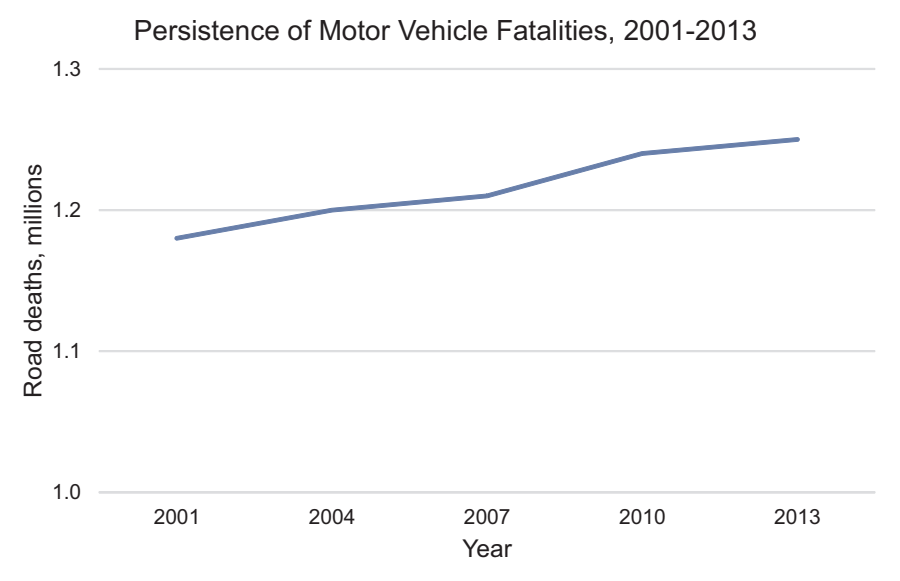

Fig. 1. Persistence of Motor Vehicle Fatalities (WHO, 2015).

\subsection{Road casualty prevention}

Automobile collisions represent one of the largest preventable causes of disability and death in the world. A series of technological innovations have reduced the rate of automobile crashes and the harms of those crashes, yet morbidity and mortality continues to rise with increasing automobile use, with well over 1.2 million fatalities annually (Fig. 1). While automated safety technologies-from seatbelts, to airbags, to automated braking - have been a large part of this slow plateau in fatalities, the advent of automated driving has the capacity to dramatically reduce the harm of driving, with this transition seeking to push toward the complete elimination of traffic fatalities (Fagnant and Kockelman, 2015). Where almost all traffic fatalities are caused by either driver error (whether caused by fatigue, distraction, or drug/alcohol use) or driver negligence (reflected in speeding, inattentiveness, misjudgment, and aggressive driving), these human factors represent an unprecedented yet unnecessary determinant of harm (NHTSA, 2016).

While it is unlikely that the theoretical reduction to zero fatalities will be realized in practice, in the short term and maybe in the long term (Sivak and Schoettle, 2015); yet, road safety issues will need to be studied during the transition to autonomous vehicles, assessing how conventional and automated vehicles interact on the road. Given that there remain large differences in injury and fatality rates across countries, it will be essential to examine the impact of autonomous vehicle policy on crash prevention during the long transition period to come. Such country-specific studies will need to understand morbidity and mortality data for those in autonomous vehicles, those in traditional vehicles, and pedestrians involved in collisions (Sivak and Schoettle, 2015). With the United Nations Sustainable Development Goals (SDGs) seeking to "ensure healthy lives" through targets to "halve the number of global deaths and injuries from road traffic accidents," automated vehicle policy can be geared toward this global health goal (UN, 2015).

\subsection{Environmental health protection}

With vehicle emission reductions a leading global priority, spurring policy efforts to limit air pollution's effects on public health and mitigate the catastrophic harms of global climate change, automated driving has the capacity to reduce these emissions through efficiencies in driving speeds and avoidance of traffic congestion (Thomopoulos and Givoni, 2015). It has long been known that key "criteria pollutants," a byproduct of fuel combustion, have a detrimental effect on human health, with air pollution epidemiology examining the correlated impacts on respiratory and cardiovascular disease from:

- Carbon monoxide (CO),

- Nitrogen dioxide $\left(\mathrm{NO}_{2}\right)$,

- Lead (Pb),

- Sulfur dioxide $\left(\mathrm{SO}_{2}\right)$,

- Ozone $\left(\mathrm{O}_{3}\right)$,

- Particulate matter, and

- Carbon dioxide $\left(\mathrm{CO}_{2}\right)$.

Transportation currently accounts for significant effects and impacts on environmental health—driven by transportation patterns and related factors, such as private car ownership, fuel efficiency, and traffic density (Dora and Phillips, 2000)—and understanding and assessing the changing impacts of autonomous transportation on environmental health will be a critical concern of global importance. Scholarly attention to environmental health impacts of autonomous vehicles thus far has concluded that these impacts-and whether they are positive or negative-depends upon a range of factors, such as the characteristics of autonomous vehicles, the transportation network's ability to adapt to these vehicles, and consumer preference as it relates to private ownership of autonomous vehicles (Morrow et al., 2014). Compounding these environmental health harms, autonomous vehicle effects on the greenhouse gas emissions 
driving global climate change are unclear, with some analyses projecting a reduced environmental impact (Brown et al., 2014; Greenblatt and Shaheen, 2015) while others project that an increase in vehicle-miles traveled could nearly double such emissions (Wadud et al., 2016). The twin environmental health risks from both air pollution and climate change are central to the SDGs, with targets focused on "air quality;" "hazardous chemicals" in the air, water, and soil; and "mitigation and adaptation to climate changes," with states seeking by 2030 to "double the global rate of improvement in energy efficiency" (UN, 2015). Long-term uncertainty remains over which automated vehicle technologies will emerge and what types of fuels they will employ, leaving public health scholars with a range of possible alternatives and outcomes related to the impact of automated vehicle adoption on environmental health. Assessing the range of technological options, their feasibility, and the possible impacts on environmental health are necessary steps for public health scholars to advance a research agenda in this area and to ensure that environmental health impacts are considered as technologies advance and automation adoption begins.

\subsection{Healthy aging promotion}

There is a need to understand the use of technology across the life course, bringing mobility to a range of populations that are currently mobility-impaired through policies that are developed to facilitate equity in mobility. Where the automobile has brought independence to billions, the independence fueled by such unprecedented mobility has not been universally shared. Technologies have sought to alleviate the burdens of driving for the elderly, from power steering to GPS navigation to parking systems, and yet the elderly continue to be burdened by disproportionately high rates of collisions (per mile driven) and fatalities (relative to middle-aged drivers) (Braver and Trempel, 2004; Preusser et al., 1998; Yee et al., 2006). With age-related characteristics affecting the sensory, motor, and cognitive functions necessary for safe driving, the physiological changes of aging are seen to lead to deterioration in physical responses and a corresponding degradation in driving abilities (Shaheen and Niemeier, 2001). Compensating for these physiological changes through self-regulation, the elderly are most likely to avoid or limit driving, resulting in low rates of automobile transportation (in miles driven) and high barriers to accessing mobility (without assistance). With rapid demographic changes posing a challenge to policymakers (Shergold et al., 2015), automated driving has the potential to provide increased mobility to aging populations (allowing for increased work, leisure, and medical care later in life) while simultaneously avoiding the collision risks caused by aging drivers (alleviating reduced driving capability). Policies are necessary to encourage automated transportation for safe driving among older drivers, with systems that are designed to overcome barriers to driving performance (Yang and Coughlin, 2014). Consistent with the SDG target to provide access by 2030 "to safe, affordable, accessible and sustainable transport systems for all ... with special attention to the needs of those in vulnerable situations, women, children, persons with disabilities and older persons" (UN, 2015), autonomous vehicle policy can seek to support the needs of mobility-limited populations through targeted subsidies and technical assistance, using transportation to make cities inclusive for all. By making active aging a reality, autonomous driving can allow increased independence, where enhanced mobility and safety facilitate wellbeing for aging societies, and it will be necessary to study the acceptance, learning, and use of automated vehicle technologies among aging drivers (Rhiu et al., 2015).

\subsection{Non-communicable disease reduction}

Motor vehicle use has long been seen to have deleterious consequences for physical activity, and transportation policy has sought to balance the efficiencies of modern transportation with the consequential increases of sedentary lifestyles (Sallis et al., 2016). Where these sedentary lifestyles are seen as a key determinant of inactivity, overweight, and obesity, such behaviors are seen as a key risk factor for non-communicable diseases (NCDs)_principally cardiovascular disease, cancer, respiratory disease, and diabetes. These diseases have expanded since the advent of the automobile, with so-called "obesogenic environments" now spreading throughout the world and leading to a corresponding increase in NCD prevalence (Swinburn et al., 2011). In seeking to "ensure healthy lives and promote well-being at all ages," SDG targets seek to realize a one-third reduction in premature mortality from NCDs by 2030 (UN, 2015). With policymakers coming to recognize the specific impact of driving time on overweight and obesity, governments have developed a series of policy proposals to address both the reduced opportunities for active transportation and the independent harms of prolonged sedentary behaviors (McCormack and Virk, 2014). These proposals will need to be investigated to understand changes to physical activity and sedentary behavior stemming from the use of autonomous vehicles. While autonomous vehicles will pose some benefits for NCD reduction-e.g., decreasing driving-induced psychological stress, a key contributor to hypertension-it will do little to ameliorate the sedentary nature of sitting in a motor vehicle, likely leading to continuing decreases in physical activity, increases in metabolic obesity, and consequences for NCDs (Biswas et al., 2015). Yet, it remains unclear how individuals will compensate for this ease in transportation, whether spending less time actively commuting or engaging in more leisure-time physical activity, and there is a dearth of comparative research across national contexts on the influence of automobile use on physical activity and weight-related outcomes (Shoham et al., 2015). To the extent that increased use of autonomous vehicles comes at the expense of walking, cycling, public transportation use, and other forms of physical activity throughout the day, this behavior shift must be studied as governments seek to address NCD reduction through transportation policy.

\subsection{Land use regulation}

The relationship between the built environment and health has been a growing research area for public health scholarship in recent years (e.g., Chen and Zhou, 2016; Frank et al., 2004, 2007; Gordon-Larsen et al., 2006; Renalds et al., 2010). The widespread adoption of autonomous vehicles will have significant impacts on how cities are planned and how their built environments are 
shaped-and thus on the health outcomes of different types of urban environments. Current research suggests urban planners at the regional level are aware of autonomous vehicles, but that none are currently including them in long-range planning due to uncertainty surrounding which technologies will prevail (Guerra, 2016). As transportation technologies evolve and city planning patterns respond-linking urban, peri-urban, and rural areas through new modes of transportation-public health scholars have an opportunity to expand the role that health impacts play in urban development. Transportation planners have embraced multimodal approaches to transportation solutions in recent years, yet the impact that automated vehicles may have on other modes of transportation is unknown. Recent research has documented that land use regulations that discourage automobile use in favor of other modes of transport produce positive health benefits (Sallis, et al., 2016; Stevenson et al., 2016). Yet, because full vehicle automation may induce higher vehicle-miles traveled (Wadud et al., 2016), uncertainty exists as to how automated vehicles will impact the future of the built environment-specifically whether autonomous vehicles will encourage denser, urban development patterns or encourage more suburban sprawl, potentially exacerbating negative health outcomes. With the SDGs seeking to further "sustainable cities," they place an emphasis on targets to "provide universal access to safe, inclusive and accessible, green and public spaces" (UN, 2015), creating an imperative to understand the urban spaces currently devoted to vehicle parking, dedicated driving, and pedestrian walking. Additionally, as practitioners (Keefe, n.d.), policymakers (NHTSA, 2016), and engineers (Furda and Vlacic, 2011) have noted, autonomous vehicles rely on infrastructure, such as road signs and lane markings, to guide their movements. With insufficient funding mechanisms and under-maintained road infrastructure (U.S. Department of Transportation, 2017), governments will face challenges in creating safe environments for autonomous vehicle deployment. A shift from personal ownership of vehicles and more efficient roadway use could have significant implications for health that will need to be considered, assessed, and understood.

\subsection{Labor market disruption}

Research has shown that steady employment and the benefits it provides and enables access to, is an important determinant of both physical and mental health (Ross and Mirowsky, 1995). Longitudinal studies have documented that unemployment negatively impacts both the physical and mental health of unemployed persons (Hergenrather et al., 2015; Jin et al., 1995; Murphy and Athanasou, 1999; Paul and Moser, 2009). While autonomous vehicles hold the promise of increasing driving efficiency-thereby decreasing traffic congestion, saving travel time, and lowering costs of transported goods-this could come at the expense of employment for millions of individuals currently employed in building, driving, and maintaining these vehicles. In 2014 in the United States alone, nearly 2.5 million Americans were employed providing ground transportation or facilitating freight trucking, with millions more in ancillary occupations (U.S. Bureau of Transportation Statistics, 2015, 2016). Although global data estimating worldwide employment in transportation are, at best, limited, the International Labor Organization has noted that the transport sector is significant for individual employment globally (ILO, 2015). As autonomous vehicles emerge as a disruptive technology, great potential exists for autonomous vehicle technology to displace taxi drivers, bus operators, delivery drivers, and freight truck operators worldwide. Cascading effects in labor markets and tax revenues are also possible, as the need for related occupations declines, including in driver licensing, insurance sales, and traffic policing. With the SDGs seeking to "promote inclusive and sustainable economic growth, employment and decent work for all" (UN, 2015), autonomous vehicles present an uncertain future, increasing economic productivity through innovation while decreasing employment in labor-intensive transportation sectors. Political and social unrest, with attendant consequences for health, may also occur with the rise of populism and extremist political parties whose ideologies may appeal to those who experience employment displacement from automation (Coyle, 2015).

\section{Conclusions}

Autonomous vehicles promise to disrupt the world at such a rapid pace that we may fail to recognize the full range of fundamental changes to underlying determinants of health. The need for transportation policy reforms will grow in the coming years, and it will be necessary to develop public health research to frame the health benefits of automated transportation and justify the inclusion of public health stakeholders in autonomous vehicle policymaking. Given the potential for automated vehicle policies to produce positive health benefits in some areas while negatively impacting health in other areas, the inclusion of public health stakeholders in shaping these policies is vital to continuing improvements in the public's health. While not all countries are equally poised to take advantage of these new technologies, there is an opportunity for comparative public health policy research to alleviate the obstacles to public health promotion along the path to a fully automated transportation grid. Where public health advocates have sought to analyze health in all policies as a basis for realizing the SDGs, transportation policy will prove increasingly relevant in structuring these new disruptive technologies as a driver of public health.

\section{Funding}

This research did not receive any specific grant from funding agencies in the public, commercial, or not-for-profit sectors.

\section{References}


Atwater, R.M., Hiscock, I.V., Maxcy, K.F., Miller, A.P., Mustard, H.S., 1938. Public health expanding. Am. J. Public Health 28 (2), $193-195$. Beauregard, R.A., 2009. Urban population loss in historical perspective: United States, 1820-2000. Environ. Plan. 41, 514-528.

Biswas, A., Oh, P.I., Faulkner, G.E., Bajaj, R.R., Silver, M.A., Mitchell, M.S., Alter, D.A., 2015. Sedentary time and its association with risk for disease incidence, mortality, and hospitalization in adults: a systematic review and meta-analysis. Ann. Intern. Med. 162, $123-132$.

Boehmer, T., Broehm, J., Robb, K., 2016. Introducing the CDC/USDOT transportation and health tool. J. Transp. Health 3 (Suppl. 2), S50.

Boniface, S., Scantlebury, R., Watkins, S.J., Mindell, J.S., 2015. Health implications of transport: evidence of effects of transport on social interactions. J. Transp. Health 2, 441-446.

Braver, E.R., Trempel, R.E., 2004. Are older drivers actually at higher risk of involvement in collisions resulting in deaths or non-fatal injuries among their passengers and other road users? Inj. Prev. 10, 27-32.

Brown, A., Gonder, J., Repac, B., 2014. An analysis of possible energy impacts of automated vehicle. In: Meyer, G., Beiker, S. (Eds.), Road Vehicle Automation. Springer, New York, pp. 137-153.

Centers for Disease Control (CDC), 2012. Recommendations for improving health through transportation policy. Available: 〈https://www.cdc.gov/transportation/ $\rangle$ (Accessed 01 March 2017).

Chapman, L., 2007. Transport and climate change: a review. J. Transp. Geogr. 15, 354-367.

Chen, P., Zhou, J., 2016. Effects of the built environment on automobile-involved pedestrian crash frequency and risk. J. Transp. Health 3 (4), $448-456$.

Chesley, A.J., 1924. The automobile as a public health hazard. Am. J. Public Health 14 (11), 917-920.

Christensen, C.M., Raynor, M.E., 2003. The Innovator's Solution: Creating and Sustaining Successful Growth. Harvard Business Review Press, Cambridge.

Coyle, D., 2015. Welcoming our robot overlords: the disruptive potential of technological progress. In: Dolphin, T. (Ed.), Technology, Globalisation and the Future of Work in Europe: Essays on Employment in a Digitised Economy. Institute for Public Policy Research, London, pp. $100-105$.

Dannenberg, A.L., Ricklin, A., Ross, C.L., Schwartz, M., West, J., White, S., Wier, M.L., 2014. Use of health impact assessment for transportation planning. Transp. Res. Rec. 2452, 71-80.

Ding, D., Gebel, K., Phongsavan, P., Bauman, A.E., Merom, D., 2014. Driving: a Road to Unhealthy Lifestyles and Poor Health Outcomes. PLoS One 9, e94602.

Dora, C., 1999. A different route to health: implications of transport policies. BMJ 318, 1686-1689.

Dora, C., Phillips, M. (Eds.), 2000. Transport, Environment, and Health. World Health Organization Regional Publications, European Series, No. 89.

Fagnant, D.J., Kockelman, K.M., 2015. Preparing a nation for autonomous vehicles: opportunities, barriers and policy recommendations. Transp. Res. Part A 77, $167-181$.

Fleetwood, J., 2017. Public health, ethics, and autonomous vehicles. Am. J. Public Health 107 (4), 532-537.

Frank, L.D., Andresen, M.A., Schmid, T.L., 2004. Obesity relationships with community design, physical activity, and time spent in cars. Am. J. Prev. Med. 27 (2), 87-96.

Frank, L.D., Sallis, J.F., Conway, T.L., Chapman, J.E., Saelens, B.E., Bachman, W., 2006. Many pathways from land use to health: associations between neighborhood walkability and active transportation, body mass index, and air quality. J. Am. Plan. Assoc. 72 (1), $75-87$.

Frank, L.D., Saelens, B.E., Powell, K.E., Chapman, J.E., 2007. Stepping towards causation: do built environments or neighborhood and travel preferences explain physical activity, driving, and obesity? Soc. Sci. Med. 65, 1898-1914.

Frumkin, H., 2002. Urban sprawl and public health. Public Health Rep. 117 (3), 201-217.

Furda, A., Vlacic, L., 2011. Enabling safe autonomous driving in real-world city traffic using multiple criteria decision making. IEEE Intel. Transp. Decis. Syst. 3 (1), 4-17.

Giles-Corti, B., Vernez-Moudon, A., Reis, R., Turrell, G., Dannenberg, A.L., Badland, H., Foster, S., Lowe, M., Sallis, J.F., Stevenson, M., Owen, N., 2016. City planning and population health: a global challenge. Lancet 388, 2912-2924.

Glancy, D.J., 2015. Autonomous and automated and connected cars-oh my! First generation autonomous cars in the legal ecosystem. Minn. J. Law Sci. Tech. 16, 619-691.

Gordon-Larsen, P., Norton, M.C., Page, P., Popkin, B.M., 2006. Inequality in the built environment underlies key health disparities in physical activity and obesity. Pediatrics 117 (2), 417-424.

Greenblatt, J.B., Shaheen, S., 2015. Automated vehicles, on-demand mobility, and environmental impacts. Curr. Sustain. Renew. Energy Rep. 2, 74-81.

Guerra, E., 2016. Planning for cars that drive themselves: metropolitan planning organizations, regional transportation plans, and autonomous vehicles. J. Plan. Educ. Res. 36 (2), 210-224.

Hall, P.M., 1914. Disposal of manure. Am. J. Public Health 4 (1), 38-42.

Hall, P.M., 1918. The collection and disposal of city waste and the public health. Am. J. Public Health 4 (3), $314-315$.

Hergenrather, K.C., Zeglin, R.J., McGuire-Kuletz, M., Rhodes, S.D., 2015. Employment as a social determinant of health: a systematic review of longitudinal studies exploring the relationship between employment status and physical health. Rehabil. Res. Policy Educ. 29, 2-26.

Hilton, G.W., 1969. Transport technology and the urban pattern. J. Contemp. Hist. 4 (3), 123-135.

International Labor Organization (ILO), 2015. Priority safety and health issues in the road transport sector. Available: 〈http://www.ilo.org/public/libdoc/ilo/2015/ 488665.pdf> (Accessed 28 December 2016).

Jin, R.L., Shah, C.P., Svoboda, T.J., 1995. The impact of unemployment on health: a review of the evidence. Can. Med. Assoc. J. 153 (5), 529-540.

Keefe, P., n.d. Autonomous vehicles drive the future of transportation infrastructure, RS \& H. Available: 〈http://www.rsandh.com/news-and-media/rsandh-in-thenews/1251-autonomous-vehicles-drive-the-future-of-transportation-infrastructure $>$ (Accessed 28 December 2016).

Khreis, H., Warsow, K.M., Verlinghieri, E., Guzman, A., Pellecuer, L., Ferreira, A., Jones, I., Heinen, E., Rojas-Rueda, D., Mueller, N., Schepers, P., Lucas, K., Nieuwenhuijsen, M., 2016. The health impacts of traffic-related exposures in urban areas: understanding real effects, underlying driving forces and co-producing future directions. J. Transp. Health 3 (3), 249-267.

Krzyzanowski, M., Kuna-Dibbert, B., Schneider, J. (Eds.), 2005. Health Effects of Transport-Related Air Pollution. World Health Organization, Copenhagen.

Lee, J.D., 2008. Fifty years of driving safety research. Hum. Factors 50 (3), 521-528.

McCormack, G.R., Virk, J.S., 2014. Driving towards obesity: a systematized literature review on the association between motor vehicle travel time and distance and weight status in adults. Prev. Med. 66, 49-55.

McShane, C., Tarr, J., 2003. The decline of the urban horse in American cities. J. Transp. Hist. 24 (2), 177-198.

Mindell, J.S., 2014. Welcome to the journal of transport and health. J. Transp. Health 1, 1.

Morrison, D.S., Petticrew, M., Thomson, H., 2003. What are the most effective ways of improving population health through transport interventions? Evidence from systematic reviews. J. Epidemiol. Commun. Health 57, 327-333.

Morrow III, W.R., Greenblatt, J.B., Struges, A., Saxena, S., Gopal, A., Millstein, D., Shah, N., Gilmore, E.A., 2014. Key factors influencing autonomous vehicles' energy and environmental outcome. In: Meyer, G., Beiker, S. (Eds.), Road Vehicle Automation. Springer, New York, pp. 127-135.

Muller, P.O., 2004. Transportation and urban form: stages in the spatial evolution of the American metropolis. In: Hanson, S., Guiliano, G. (Eds.), Geography of Urban Transportation. Guilford, New York, pp. 59-85.

Murphy, G.C., Athanasou, J.A., 1999. The effect of unemployment on mental health. J. Occup. Organ Psychol. 72, 83-99.

Paul, K.I., Moser, K., 2009. Unemployment impairs mental health: meta-analyses. J. Vocat. Behav. 74, $264-282$.

Preusser, D.F., Williams, A.F., Ferguson, S.A., Ulmer, R.G., Weinstein, H.B., 1998. Fatal crash risk for older drivers at intersections. Accid. Anal. Prev. 30 (2), 151-159.

Renalds, A., Smith, T.H., Hale, P.J., 2010. A systematic review of built environment and health. Fam. Commun. Health 33 (1), 68-78.

Rhiu, I., Kwon, S., Bahn, S., Yun, M.H., Yu, W., 2015. Research issues in smart vehicles and elderly drivers: a literature review. Int. J. Hum. Comput. Interact. 31 (10), 635-666.

Ross, C.E., Mirowsky, J., 1995. Does employment affect health? J. Health Soc. Behav. 36 (3), 230-243.

Sallis, J.F., Bull, F., Burdett, R., Frank, L.D., Griffiths, P., Giles-Corti, B., Stevenson, M., 2016. Use of science to guide city planning policy and practice: how to achieve healthy and sustainable future cities. Lancet 388, 2936-2947.

Shaheen, S.A., Niemeier, D.A., 2001. Integrating vehicle design and human factors: minimizing elderly driving constraints. Transp. Res. Part C 9, 155-174. 
Shergold, I., Lyons, G., Hubers, C., 2015. Future mobility in an ageing society - Where are we heading? J. Transp. Health 2, 86-94.

Shoham, D.A., Dugas, L.R., Bovet, P., Forrester, T.E., et al., 2015. Association of car ownership and physical activity across the spectrum of human development: modeling the Epidemiologic Transition Study (METS). BMC Public Health 15, 173.

Sivak, M., Schoettle, B., 2015. Road Safety with Self-Driving Vehicles: General Limitations and Road Sharing with Conventional Vehicles. University of Michigan Transportation Research Institute, Report No. UMTRI-2015-2.

Sperling, D., Gordon, D., 2009. Two Billion Cars: driving Toward Sustainability. Oxford University Press, New York.

Stevenson, M., Thompson, J., Hérick de Sá, T., Ewing, R., Mohan, D., McClure, R., Roberts, I., Tiwari, G., Giles-Corti, B., Sun, X., Wallace, M., Woodcock, J., 2016. Land use, transport, and population health: estimating the health benefits of compact cities. Lancet 388, $2925-2935$.

Swinburn, B.A., Sacks, G., Hall, K.D., McPherson, K., Finegood, D.T., Moodie, M.L., Gortmaker, S.L., 2011. The global obesity pandemic: shaped by global drivers and local environments. Lancet. 378, 804-814.

Thomas, V.M., 1995. The elimination of lead in gasoline. Annu. Rev. Energy Environ. 20, 301-324.

Thomopoulos, N., Givoni, M., 2015. The autonomous car-a blessing or a curse for the future of low carbon mobility? An exploration of likely vs. desirable outcomes. Eur. J Futur. Res. 3, 14.

Thompson, C., 2016. Elon Musk: Fully autonomous Tesla will drive across the country by the end of 2017, Business Insider. Available: 〈http://www.businessinsider. com/elon-musk-autonomous-tesla-drive-across-country-by-end-of-2017-2016-10> (Accessed 28 December 2016).

U.S. Bureau of Transportation Statistics, 2015. Freight Facts and Figures 2015. Available: 〈http://www.rita.dot.gov/bts/sites/rita.dot.gov.bts/files/FFF_complete.pdf〉 (Accessed 24 November 2016).

U.S. Bureau of Transportation Statistics, 2016. Passenger Facts and Figures 2016. Available: 〈http://www.rita.dot.gov/bts/sites/rita.dot.gov.bts/files/PTFF\%202016 full.pdf> (Accessed 24 November 2016).

U.S. Department of Transportation, 2017. Beyond Traffic 2045. Available: 〈https://www.transportation.gov/sites/dot.gov/files/docs/BeyondTraffic_tagged_508_final. pdf> (Accessed 14 February 2017).

U.S. National Highway Traffic Safety Administration (NHTSA), 2013. U.S. Department of Transportation releases policy on automated vehicle development. Available: 〈http://www.nhtsa.gov/About-NHTSA/Press-Releases/U.S.-Department-of-Transportation-Releases-Policy-on-Automated-Vehicle-Development〉 (Accessed 24 November 2016).

U.S. National Highway Traffic Safety Administration (NHTSA), 2016. Federal Automated Vehicles Policy: Accelerating the Next Revolution in Roadway Safety. U.S. Department of Transportation, Washington.

United Nations (UN), 2015. Sustainable Development Goals. United Nations, New York. Available: 〈http://www.un.org/sustainabledevelopment/sustainabledevelopment-goals $/>$ (Accessed 24 November 2016).

Wadud, Z., MacKenzie, D., Leiby, P., 2016. Help or hindrance? The travel, energy, and carbon impacts of highly automated vehicles. Transp. Res. Part A 86, 1-18.

Wells, C., 2014. Rebuilding the city, leaving it behind: transportation and the environmental crisis in turn-of-the-century American cities. J. Transp. Hist. 35 (2), 183-199.

Widener, M.J., Hatzopoulou, M., 2016. Contextualizing research on transportation and health: a systems perspective. J. Transp. Health 3 (3), $232-239$.

Woodcock, J., Edwards, P., Tonne, C., Armstrong, B.G., Ashiru, O., Banister, D., Beevers, S., Chalabi, Z., Chowdhury, Z., Cohen, A., Franco, O.H., Haines, A., Hickman, R., Lindsay, G., Mittal, I., Mohan, D., Tiwari, G., Woodward, A., Roberts, I., 2009. Public health benefits of strategies to reduce greenhouse-gas emissions: urban land transport. Lancet 374, 1930-1943.

World Bank, 1994. World Development Report: Infrastructure for Development. Oxford University Press, New York.

World Health Organization (WHO), 2015. Global status report on road safety 2015. Available: 〈http://www.who.int/violence_injury_prevention/road_safety_status/ 2015/en/> (Accessed 30 December 2016).

Yang, J., Coughlin, J.F., 2014. In-vehicle technology for self-driving cars: advantages and challenges for aging drivers. Int. J. Automot. Technol. 15 (2), 333-340.

Yee, W.Y., Cameron, P.A., Bailey, M.J., 2006. Road traffic injuries in the elderly. Emerg. Med. J. 23, $42-46$. 